\title{
Stress-Induced Sensitization and Glucocorticoids. I. Sensitization of Dopamine-Dependent Locomotor Effects of Amphetamine and Morphine Depends on Stress-Induced Corticosterone Secretion
}

\author{
Véronique Deroche, Michela Marinelli, Stefania Maccari, Michel Le Moal, Hervé Simon, and \\ Pier Vincenzo Piazza \\ Psychobiologie des Comportements Adaptatifs, INSERM U259, Université de Bordeaux II, Domaine de Carreire, \\ 33077 Bordeaux Cedex, France
}

Repeated exposures to stress sensitize motor and addictive effects of drugs of abuse. Recently, it has been shown that stress-induced behavioral sensitization depends on the secretion of glucocorticoids. We investigated if sensitization of dopamine-dependent effects of psychostlmulants and opioids was influenced by glucocorticoids. Sensitization of the dopaminergic response to drugs is considered the neural substrate of behavioral sensitization and has been implicated in vulnerability to drug abuse. Dopamine-dependent effects of psychostimulants and opioids were evaluated by injecting either amphetamine into the nucleus accumbens ( $10 \mu \mathrm{g} / \mathrm{side}$ ) or morphine into the ventral tegmental area (VTA) ( $1 \mu \mathrm{g} /$ side). The locomotor response to psychostimulants and opioids injected in these brain areas depends on the mesencephalic dopaminergic transmission. Drug-induced locomotion was compared in male rats in which corticosterone secretion was either in +tct or experimentally suppressed by an adrenalectomy associated with a substitutive treatment reproducing basal levels of the hormone. Eight days of food restriction ( $80 \%$ of the initial body weight) were used as a stressor. Suppression of stress-induced corticosterone secretion abolished food restriction-induced sensitization of the locomotor effects of intra-accumbens amphetamine and intraVTA morphine. This effect was corticosterone dependent since the restoration of corticosterone levels in the range of those induced by stress totally reinstates sensitization. Our results suggest that glucocorticoids control stress-induced sensitization by changing the sensitivity of the mesencephalic dopaminergic transmission to drugs of abuse. Since dopaminergic effects of drugs are related to their addictive properties, secretion of glucocortlcolds may be one of the factors determining the enhanced vulnerability to drugs observed in stressed subjects.

[Key words: sensitization, glucocorticoids, corticosterone, food restriction, amphetamine, morphine, dopamine,

\footnotetext{
Received Apr. 6, 1995; revised June 13, 1995; accepted June 21, 1995.

This work was supported by Institut National de la Santé et de la Recherche Médicale (INSERM), Université de Bordeaux II, Conseil Régional d'Aquitaine Pôle Médicament Aquitaine, Ministère de la Recherche et de l'Enseignentent Supérieur. M.M. was supported by a grant of the "Dottorato di Ricerca in Neuroscienze" University of Rome.

Correspondence should be addressed to Dr. Pier Vincenzo Piazza, INSERM U259, Rue Camille Saint-Säens, 33077 Bordeaux Cedex, France.

Copyright $(C) 1995$ Society for Neuroscience $0270-6474 / 95 / 157181-08 \$ 05.00 / 0$
}

nucleus accumbens, ventral tegmental area, psychomotor effects, drug abuse]

Life experiences, and in particular exposure to stress, can increase the sensitivity to psychomotor and reinforcing effects of drugs of abuse, a phenomenon known as behavioral sensitization. For example, exposure to various stressors increases the locomotor response to psychostimulants and opioids (Robinson and Becker, 1986; Kalivas and Stewart, 1991; Robinson and Berridge 1993; Stewart and Badiani, 1993) and the propensity to develop their intravenous or oral self-administration (Alexander et al., 1978; Hadaway et al., 1979; Schenk et al., 1987; Bozarth et al., 1989; Piazza et al., 1990; Maccari et al., 1991; Deminière et al., 1992; Shaham et al., 1992; Shaham and Stewart, 1994).

Sensitization of the dopaminergic response to psychostimulants and opioids seems the principal neural substrate of behavioral sensitization (Robinson and Becker, 1986; Kalivas and Stewart, 1991; Robinson and Berridge, 1993). First, behavioral effects of psychostimulants and opioids depend on the mesencephalic dopaminergic transmission (Fibiger and Phillips, 1988; Koob and Bloom, 1988; Wise and Rompre, 1989; Le Moal and Simon, 1991). Second, the increase in extracellular concentrations of dopamine induced by these drugs is enhanced in animals sensitized by stress (Sorg and Kalivas, 1991). Third, behavioral sensitization is suppressed by lesions (Post et al., 1988) or pharmacological blockade (Stewart and Vezina, 1989; Vezina and Stewart, 1989) of the mesencephalic dopaminergic transmission.

Recently it has been demonstrated that stress-induced behavioral sensitization depends on glucocorticoid hormones. Removal of the adrenal glands, the major source of endogenous glucocorticoids, suppresses the sensitization of the locomotor response to amphetamine and morphine induced by different stressors (Deroche et al., 1992a, 1993a, 1994). Furthermore, repeated administration of corticosterone, the principal glucocorticoid in the rodent, can substitute for stress and sensitize the locomotor response to amphetamine (Deroche et al., 1992b).

In this report, we investigated if stress-induced sensitization of the dopaminergic response to psychostinulants and opioids depends on glucocorticoids. We studied the influence of corticosterone on the sensitization of the locomotor response to amphetamine and morphine injected, respectively, into the nucleus accumbens and the ventral tegmental area (VTA). These central effects of amphetamine (Kelly and Iversen, 1976; Delfs et al., 1990) and morphine (Joyce and Iversen, 1979; Kalivas et al., 
1983; Vezina and Stewart, 1984) depend on the mesencephalic dopaminergic transmission. Glucocorticoids may act on sensitization through dopamine. Mesencephalic dopaminergic neurons have corticosteroid receptors (Härfstrand et al., 1986) and glucocorticoids can modify the metabolic activity (Versteeg et al., 1983; Rothschild et al., 1985) and the postsynaptic sensitivity of the dopaminergic transmission (Faunt and Crocker, 1988, 1989).

Amphetamine- and morphine-induced locomotion were studied in rats in which corticosterone secretion was either intact or experimentally controlled. In the latter case, animals were adrenalectomized and submitted to substitutive treatments reproducing either basal or stress levels of corticosterone. Food-restriction was the stressor used to induce sensitization. This condition powerfully increases corticosterone secretion (Brooks et al., 1990) and sensitizes the locomotor (Campbell and Fibiger, 1971) and reinforcing (Carroll et al., 1979; Carroll and Meisch, 1981; Carroll, 1982; Papasava and Singer, 1985; De Vry et al., 1989) effects of psychostimulants and opioids.

\section{Materials and Methods}

\section{Subjects}

Males Sprague-Dawley rats (Iffa Credo, Lyon, France) weighing 280 $300 \mathrm{gm}$ were used. Animals were individually housed with ad libitum access to food and water for at least 2 weeks before the beginning of the experiments. A constant dark-light cycle (on 6 A.M., off 20 P.M.) was maintained in the animal house. Temperature $\left(22^{\circ} \mathrm{C}\right)$ and humidity $(60 \%)$ were controlled.

\section{General methods}

Drugs and drug administration. Corticosterone 21-hemisuccinate (AGRAR, Italy) was used and concentrations expressed as corticosterone base. D-Amphetamine sulfate and morphine sulfate were dissolved in a vehicle solution reproducing the electrolytical content of the cerebrospinal fluid and containing: 125 $\mathrm{mM} \mathrm{NaCl}, 1.2 \mathrm{mM} \mathrm{CaCl}, 2.7 \mathrm{mM} \mathrm{KCl}, 1.0 \mathrm{~mm} \mathrm{MgCl}_{2}$, and buffered with $0.2 \mathrm{mM}$ of $\mathrm{Na}_{2} \mathrm{HPO}_{4} / \mathrm{NaH}_{2} \mathrm{PO}_{4}$ at $\mathrm{pH}$ 7.4. D-Amphetamine sulfate was bilaterally injected in the nucleus accumbens at a dose of $10 \mu \mathrm{g} / \mathrm{side}$. Morphine sulfate was bilaterally injected in the ventral tegmental area (VTA) at a dose equivalent to $1 \mu \mathrm{g} / \mathrm{side}$ of morphine base. Central administrations were performed in unrestrained rats over a period of 90 sec in a volume of $1 \mu \mathrm{l} /$ side. The injection cannulas (30 ga stainless steel) were descended $2 \mathrm{~mm}$ below the guide cannulas and left in place for $60 \mathrm{sec}$ both before and after the administration period.

Locomotor activity. Locomotor activity was measured in a circular corridor $(10 \mathrm{~cm}$ wide and $70 \mathrm{~cm}$ in diameter). Four photoelectric cells placed at the perpendicular axis of the. apparatus automatically recorded locomotion. Since it has been previously shown that locomotor response to novelty is correlated with the sensitivity to the psychomotor effects of drugs (Piazza et al., 1989; Hooks et al., 1991a,b; Deroche et al., 1993b), we ensured a homogenous distribution of this factor throughout the different experimental groups. For this purpose, after a period of one week of habituation to the housing condition and before any other manipulation, animals were tested for locomotor response to novelty and evenly distributed in the different experimental groups according to their activity score cumulated over $2 \mathrm{hr}$ of testing.

Food restriction. Rats were daily weighed at 6 P.M. The ration of food was given each evening at 7 P.M. The first day of restriction, all rats received $4 \mathrm{gm}$ of food. The following days, the ration of food was adapted to each rat so that the body weight attained $80 \%$ of the prerestriction weight over $6 \mathrm{~d}$. Body weight was stabilized at this percentage for at least $2 \mathrm{~d}$ before testing.

Stereotaxic implantation. Under sodium pentobarbital $(50 \mathrm{mg} /$ $\mathrm{kg}$ i.p.) anaesthesia, rats were placed in a stereotaxic apparatus (Kopf instruments) with incisor bar placed $5.0 \mathrm{~mm}$ above the interaural line. Chronic guide cannulas $(23 \mathrm{ga} \times 10 \mathrm{~mm}$ stainless steel), positioned $2 \mathrm{~mm}$ above the final injection site, were implanted bilaterally according to the stereotaxic atlas of Pellegrino et al. (1979). The guide cannulas were secured in place with the use of skull screws and dental cement. Removable $10 \mathrm{~mm}$ stainless stccl blockers were inserted in the guide cannulas to prevent clogging. The stereotaxic coordinates relative to bregma were: $\mathrm{A} / \mathrm{P}=+3.7 \mathrm{~mm}, \mathrm{~L}= \pm 1.6 \mathrm{~mm}, \mathrm{~V}=-5.6 \mathrm{~mm}$ for the nucleus accumbens and $\mathrm{A} / \mathrm{P}=-3.3 \mathrm{~mm}, \mathrm{~L}= \pm 1.6 \mathrm{~mm}, \mathrm{~V}=-6.9$ $\mathrm{mm}$ for the VTA.

Adrenalectomy. Adrenalectomy was performed, under ether anaesthesia, between 9 and 11 A.M., via the dorsal route. Shamoperated animals underwent the same surgical procedure except that the adrenals were not removed. Following surgery, $\mathrm{NaCl}$ $(0.9 \%)$ was added to the drinking water of adrenalectomized rats.

Corticosterone replacement treatments and experimental groups. Adrenalectomized animals were assigned to different experimental groups receiving different corticosterone replacement treatments aimed to reproduce either basal corticosterone levels or levels observed during stress:

Basal corticosterone groups. Two different corticosterone replacement treatments were uscd in order to reproduce basal corticosterone secretion in the amphetamine and morphine experiments. For the amphetamine experiment, the treatment was designed to reproduce the diurnal levels of the hormone, whereas for the morphine experiment it attempted to mimic the entire circadian rhythm of corticosterone secretion. In fact, it has been previously shown that in adrenalectomized animals the psychostimulant-induced locomotor activity is recovered by a substitutive treatment reproducing the diurnal levels of corticosterone (Marinelli et al., 1994). On the contrary, locomotor response to morphine is fully reinstated only when the entire circadian pattern of corticosterone secretion is reinstated (Marinelli et al., 1994).

In order to reproduce basal diurnal levels, animals were implanted, at the time of adrenalectomy, with a subcutaneous pellet of corticosterone which releases, over a period of $20 \mathrm{~d}$, a stable amount of the hormone, in the range of physiological diurnal levels. The corticosterone pellet contained $50 \mathrm{mg}$ of corticosterone base adjusted to $100 \mathrm{mg}$ with cholesterol (Meyer et al.. 1979). In order to reproduce the entire circadian rhythm of corticosterone secretion, adrenalectomized animals were implanted with the above described corticosterone pellets and received corticosterone $(50 \mu \mathrm{g} / \mathrm{ml})$ in the drinking water from 7 P.M. to 8 A.M. Corticosterone in the drinking water reproduced the noclurnal rise in plasma corticosterone levels (Marinelli et al., 1994).

Stress corticosterone groups. In order to increase corticosterone levels in the range of those observed during stress, adrenalectomized rats implanted with a corticosterone pellet received corticosterone $(100 \mu \mathrm{g} / \mathrm{ml})$ in their drinking solution throughout the entire experiment. This treatment was started concomitantly with food restriction.

Corticosterone Assay. Blood for corticosterone assay was collected in heparinized tubes. Plasma, obtained after centrifugation, was stored at $-20^{\circ} \mathrm{C}$ until assay. Plasma corticosterone was measured by radioimmunoassay (RIA kit, ICN Biomedicals. 
Inc.) using a highly specific corlicosterone antiserum with a detection threshold of $0.1 \mu \mathrm{g} / 100 \mathrm{ml}$.

Histology. At the end of the experiments, the animals were anesthetized with sodium pentobarbital and perfused transcardially with $50 \mathrm{ml}$ of $0.9 \%$ saline and then with $50 \mathrm{ml}$ of $10 \%$ formalin. Brains were removed and stored in $10 \%$ formalin until histology. Brains were cut on a freezing microtome (Kryostat System, Dittes-Dispuva, Germany) and the precise location of the probe was determined in coronal serial sections using thionin staining. Only the animals with correctly placed implantations were included in the statistical analysis.

\section{Procedures}

Experiment 1: effect of stress-induced corticosterone secretion on the locomotor response to intra-accumbens injection of amphetamine. Forty-eight rats were implanted with guide cannulas into the nucleus accumbens. After $10 \mathrm{~d}$ of recovery 20 rats were sham-operated (Controls) and 28 rats were adrenalectomized and implanted with a subcutaneous corticosterone pellet. Four days later animals were divided in five experimental groups. The first two groups, Controls $(n=9)$ and Basal Corticosterone $(n=9)$ were fed ad libitum. The other three groups, Controls $(n=10)$, Basal Corticosterone $(n=10)$ and Stress Corticosterone $(n=10)$ were food-restricted. After $8 \mathrm{~d}$ of these treatments, the animals were tested over $2 \mathrm{~d}$ for the locomotor response to the intraaccumbens injection of either vehicle or amphetamine. The first day, the animals were placed in the circular corridor at 10 A.M. and after a $2 \mathrm{hr}$ period of habituation to the apparatus, they were injected with vehicle and their locomotor response was recorded for $2 \mathrm{hr}$ over $10 \mathrm{~min}$ intervals. The second day, the same procedure was repeated, but instead of receiving intra-accumbens vehicle, the animals were administered with amphetamine.

In order to verify that the administration of corticosterone $(100 \mu \mathrm{g} /$ $\mathrm{ml}$ ) in the drinking solution of food-restricted animals increased corticosterone levels above those observed in basal conditions in ad libitum fed rats, two supplementary groups of Controls $(n=7)$ and Stress Corticosterone $(n=7)$ rats were used. Animals in both groups were sacrificed at 9 P.M. and blood collected for corticosterone assay.

Experiment 2: effect of stress-induced corticosterone secretion on the locomotor response to intra-VTA injection of morphine. Thirty-eight rats were implanted with guide cannulas into the VTA. After $10 \mathrm{~d}$ of recovery, 13 rats were sham-operated (Controls) and 20 rats were adrenalectomized, implanted with corticosterone pellets and received corticosterone $(50 \mu \mathrm{g} / \mathrm{ml})$ in the nocturnal drinking water. Four days later, five experimental groups similar to those of the previous experiment were constituted, respectively: Ad libitum Fed Controls $(n=7)$, Ad libitum Fed Basal Corticosterone $(n=6)$, Food-restricted Controls ( $n$ $=6$ ), Food-restricted Basal Corticosterone $(n=8)$, Food-restricted Stress Corticosterone $(n=6)$. Diurnal and nocturnal fluid intakes were measured throughout the experiment. After $8 \mathrm{~d}$ of food restriction, the locomotor response to intra-VTA vehicle or morphine was determined using the same procedure employed in the amphetamine experiment. I ocomotor response to intra-VTA injection was recorded for $3 \mathrm{hr}$ over $30 \mathrm{~min}$ intervals.

Statistical analysis. Two types of analyses of variance (ANOVA) were used in order to compare the locomotor activity scores of the different experimental groups in response to either drug or vehicle injections. The first analysis had two between factors: Basal Corticosterone Secretion and Food Restriction (two levels cach). This analysis compared the Controls and the Basal Corticosterone groups either foodrestricted or ad libitum fed. The second type of analysis had one between factor (Treatment) and compared food-restricted animals in the Controls, Basal Corticosterone and Stress Corticosterone groups. The two types of analyses had "Time" as within factor (12 levels for the amphetamine experiment, 6 levels for the morphine experiment). ANOVA was also used in order to study changes in fluid intake and plasmatic corticosterone levels.

\section{Results}

Experiment 1: effect of stress-induced corticosterone secretion on the locomotor response to intra-accumbens injection of amphetamine

Neither food restriction $[F(1,34)=1.325, P=0.257]$ nor manipulations of corticosterone secretion $[F(1,34)=0.671, P=$
$0.418]$ modified the locomotor response to intra-accumbens vehicle injections (Fig. 1). However, food restriction increased the locomotor response to intra-accumbens amphetamine [Food Restriction effect, $F(1,34)=3.83, P<0.05$ ] and this effect was abolished by fixing corticosterone levels in the range of the basal ones [Basal Corticosterone secretion $\times$ Food Restriction interaction, $F(1,34)=3.742, P<0.05$ ] (Fig. 1). Thus, in the groups with an intact corticosterone secretion (Controls), food-restricted rats had a higher locomotor response to amphetamine than ad libitum fed animals $[F(1,17)=6.599, P<0.02]$. On the contrary, in the groups in which stress-induced corticosterone secretion was suppressed (Basal Corticosterone groups), ad libitum fed and food-restricted animals did not differ $[F(1,17)=0.00$, $P=0.98$ ] and had a locomotor response similar to the one of ad libitum fed sham rats $[F(1.16)=0.219, P=0.648$ and $F(1.17)=0.322, P=0.577$, respectively $]$.

Addition of corticosterone (100 $\mathrm{g} / \mathrm{m}$ II) in drinking water significantly increased nocturnal levels of corticosterone $[F(1,12)$ $=4,42 P<0.05]$ bringing them in the range of those classically observed during stress. Corticosterone levels $(\mu \mathrm{g} / 100 \mathrm{ml})$ were: Corticosterone group $=38 \pm 8.9$, Controls $=18.3 \pm 4$. This treatment also restored the increase in locomotor response to amphetamine induced by food restriction (Fig. 2, left panel). Thus, food restricted rats with an intact corticosterone secretion had a higher locomotor response to amphetamine than foodrestricted Basal Corticosterone rats $[F(1,18)=12,68, P<$ $0.002]$, whereas they did not differ from Stress Corticosterone animals $[F(1,18)=0.362, P=0.55]$.

\section{Experiment 2: effect of stress-induced corticosterone secretion on the locomotor response to intra-VTA injection of morphine}

Neither manipulations of corticosterone secretion $[F(1.23)=$ $1.43, P=0.24]$ nor food restriction $[F(1.23)=2.45, P=0.129]$ modified the locomotor response to vehicle injections (Fig. 3). Food restriction prolonged the locomotor response to morphine [Food Restriction $\times$ Time interaction, $F(5,115)=5.11, P<$ $0.001]$ and this effect was suppressed by fixing corticosterone levels in the range of the basal ones [Basal Corticosterone secretion $\times$ Food Restriction $\times$ Time interaction, $F(5,115)=2.26$, $P<0.02$ ] (Fig. 3). Indeed, food-restricted rats with an intact corticosterone secretion showed a longer locomotor response to morphine than ad libitum fed controls $[F(5,55)=4.32, P<$ $0.002]$, whereas this effect disappeared in food restricted rats in which stress-induced corticosterone secretion was suppressed (Food-restricted Basal Corticosterone). Ad libitum fed Basal Corticosterone and ad libitum fed Controls animals did not differ for their response to morphine in total $\mid F(1,11)=0.014, P=$ $0.90]$ or over time $[F(5,55)=0.17, P=0.17\}$. However during the first hour after the injection of morphine Food-restricted Basal Corticosterone rats presented a smaller response to morphine than ad libitum fed Controls [Food Restriction $\times$ Time interaction, $F(5,65)=2.52, P<0.05]$ and ad libitum fed Basal Corticosterone rats [Food Restriction $\times$ l'ime interaction, $F(5.60)=3.53, P<0.01]$. This result may be explained by the fact that food restriction decreased the nocturnal intake of water. Indeed, it has been previously shown that the reinstatement of hasal Iocomotor response to morphine depends on the addition of corticosterone to the nocturnal drinking water (Marinelli et al., 1994). The mean nocturnal intake (over the 8 nights of the food restriction period) was lower in food-restricted Basal Corticosterone rats $(31.88 \pm 2.64 \mathrm{ml})$ than in the ad libitum fed 

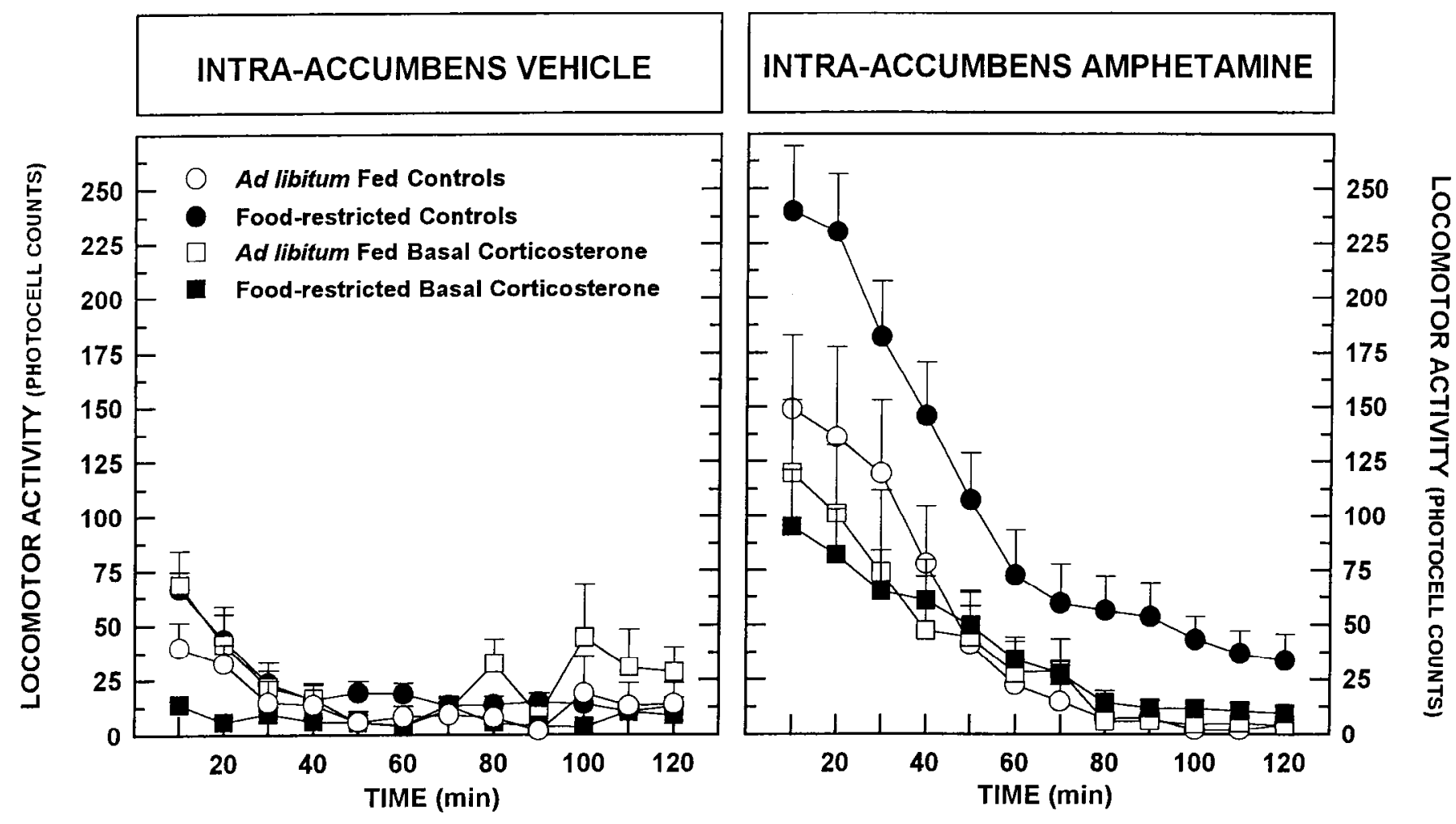

Figure 1. Effects of food restriction on the locomotor response to the intra-accumbens injection of either vehicle ( $1 \mu \mathrm{l} / \mathrm{side}$ ) or amphetamine (10 $\mu \mathrm{g} / \mathrm{side}$ ) in rats with an intact (Controls) or suppressed stress-induccd corticosterone secretion (Basal Corticosterone). In the Basal Corticosteronc groups plasmatic levels of corticosterone were fixed in the range of basal ones by adrenalectomy and substitutive treatments. Food restriction (80\% of initial body weight) did not modify the locomotor response to vehicle in Controls and Basal Corticosterone animals. Suppression of stressinduced corticosterone secretion abolished the sensitization of the locomotor response to amphetamine induced by food restriction. In the Control groups, food-restricted rats had a higher locomotor response to amphetamine than ad libitum fed animals $[F(1.17)=6.599, P<0.02]$. On the contrary, food restriction did not increased the locomotor response to amphetamine in Basal Corticosterone animals.

Basal Corticostcronc animals $(43.5 \pm 5.3 \mathrm{ml})[F(1,12)=4.44$ $P<0.05]$.

The elevation of corticosterone levels in the range of those observed during stress restored the increase in the locomotor response to morphine induced by food restriction. Thus, food restricted animals with an intact corticosterone secretion had a higher $[F(1,12)=7.08, P<0.02]$ and longer $[F(5,60)=2.29$, $P<0.05]$ locomotor response to morphine than food-restricted rats in which stress-induced corticosterone secretion was suppressed, whereas they did not differ from food-restricted StressCorticosterone animals for the locomotor response to morphine in total $[F(1,10)=0.031, P=0.91]$ or over time [Food Restriction $\times$ Time interaction, $F(5,50)=0.66, P=0.64$ ] (Fig. 2, right panel).

\section{Discussion}

The results presented in this report suggest that glucocorticoids control stress-induced behavioral sensitization by changing the response of the mesencephalic dopaminergic transmission to drugs. Thus, food restriction-induced sensitization of the locomotor response to intra-accumbens amphetamine or intra-VTA morphine was suppressed in adrenalectomized animals in which corticosterone levels were fixed in the range of basal ones. These findings point to an involvenent of dopamine because the locomotor activity induced by the injection of psychostimulants in the accumbens (Kelly and Iversen, 1976; Delfs et al., 1990) or of opioids in the VTA (Joyce and Iversen, 1979; Kalivas et al., 1983; Vezina and Stewart, 1984) depends on the activation of the mesence- phalic dopaminergic transmission. Sensitization of dopamine-mediated responses to psychostimulants and opioids was specifically dependent on stress-induced secretion of corticosterone. Indeed, sensitization was reinstated when adrenalectomized rats received corticosterone at doses that induced plasma levels of the hormone that were in the range of those induced by stress.

Sensitization of reinforcing and motor effects of drugs can also be induced by repeated injection of psychostimulants and opioids (Robinson and Berridge, 1993). Stress- and drug-induced sensitization have common final effects on drug response, and are often combined under the common definition of behavioral sensitization (Kalivas and Stewart, 1991). However, generalizations from stress-induced sensitization to drug-induced one require caution, in fact the two phenomenon differ in many aspects. For example, the development and expression of druginduced sensitization is facilitated when the injections are intermittent and spaced by an interval of a few days and when a long drug-free period is left between the treatment and the challenge injections (Robinson and Becker, 1986; Kalivas and Stewart, 1991). Furthermore, the expression of drug-induced sensitization is largely controlled by learning phenomenon and in particular by the conditioning of drug effects to environmental cues (Stewart and Badiani, 1993). All these parameters do not seem to play an important role in stress-induced sensitization. Behavioral sensitization has been induced by stressors that are continuous, such as food restriction (Camphell and Fibiger, 1971; Deroche et al., 1993) and social isolation (Schenk et al., 1987; Deroche et al., 1994), as well as by stressors that are of 



Figure 2. Locomotor response to the intra-accumbens injection of amphetamine $(10 \mu \mathrm{g} / \mathrm{side})$ or of the intra-VTA injection of morphine (1 $\mu \mathrm{g} /$ side) in groups of food-restricted rats differing for corticosterone secretion. Controls, Rats with an intact corticosterone secretion. Basal Corticosterone, Rats whose plasmatic levels of corticosterone have been fixcd in the range of basal ones by adrenalectomy and substitutive treatments. Stress Corticosterone, Animals in which stress-induced levels of corticosterone have been reinstated by the addition of corticosterone ( $100 \mu \mathrm{g} / \mathrm{ml})$ in the drinking water. Food-restricted animals ( $80 \%$ of their initial body weight) with an intact corticosterone secretion (Controls) had a higher locomotor response to amphetamine $[F(1.18)=12.68, P<0.002]$ and a higher $[F(1,12)=7.08, P<0.02]$ and longer $[F(5,60)=2.29, P<$ $0.05]$ locomotor response to morphine than food restricted rats in which stress-induced corticosterone secretion was suppressed (Basal Corticosterone), but did not differ from Stress Corticosterone animals.

short duration, such as electric foot-shock, restraint, or tail pinch (Antelman et al., 1980; Piazza et al., 1991; Deroche et al., 1992; Goeders et al., 1994; Shaham and Stewart 1994), and this occurs both when the stress is administered daily and when variable time intervals separate the stress sessions. Also, the interval between the stress and the challenge injection does not seem to influence the expression of stress-induced behavioral sensitization. For example, after the same stress schedule, a similar degree of sensitization has been observed both when the challenge injection substituted the daily stress session (Antelman et al., 1980) or when a 1 week stress-free period was left before the injection of the drug (Piazza et al., 1990). Finally, stress-induced sensitization has also been found when it is impossible to establish any temporal or environmental link between the stressor and the injection (Piazza et al., 1989, 1990; Maccari et al., 1991; Deroche et al., 1992a). The most striking example along this line is the finding of behavioral sensitization in adult animals that were stressed during the last 2 weeks of prenatal life (Deminière et al., 1992).

Our findings confirm and extend current knowledge on the effect of food-restriction on the sensitivity to drugs of abuse. Indeed, several works have shown that food-restriction increases oral or intravenous self-administration of opioids (Carroll et al., 1979; Carroll and Meisch, 1981; Carroll, 1982) and psychostimulants (Papasava and Singer, 1985; De Vry et al., 1989) as well as sensitizes the locomotor response to a systemic injection of these drugs (Campbell and Fibiger, 1971; Deroche et al., 1993a). We show here, for the first time, that the effects of food restriction are mediated by changes in the neuronal response to drugs. Thus, food restriction-induced sensitization is also found when the behavior is induced by central injection of psychostimulants or opioids.

Stress-induced corticosterone secretion may modify dopamine-dependent response to amphetamine and morphine by a direct action on dopaminergic transmission. Two possible mechanisms are likely. First, corticosterone could act directly on dopaminergic neurons modifying drug-induced increases in the extracellular concentration of dopamine. Mesencephalic dopaminergic cells possess glucocorticoid receptors (Härfstrand et al., 1986) and evidences exist that corticosterone can modify metabolism (Ho-Van-Hap et al., 1967; Rothschild et al., 1985), extracellular concentrations (Imperato et al., 1989; Mittleman et al., 1992) and reuptake (Gilad et al., 1987) of dopamine. Second, corticosterone could modify the action of dopamine on the postsynaptic side. Though, contrasting reports exist in the literature, some evidence suggests that glucocorticoids could facilitate the postsynaptic dopaminergic transmission (Faunt and Crocker, 1988, 1989; Biron et al., 1992).

Stress-induced corticosterone secretion could also modulate dopamine-dependent locomotor responses to drugs by acting on other neuronal systems. The opioid system is one of the most probable corticosterone targets. First, opioid afferents to dopaminergic neurons modulate stimulant effects of drugs (Kalivas, 1985). Second, fond-restriction enhances opioid activity in the CNS (Knuth and Friesen, 1983; Tsujii et al., 1986a,b; Vaswani et al., 1986). Third, corticosterone potentiates both biochemical 


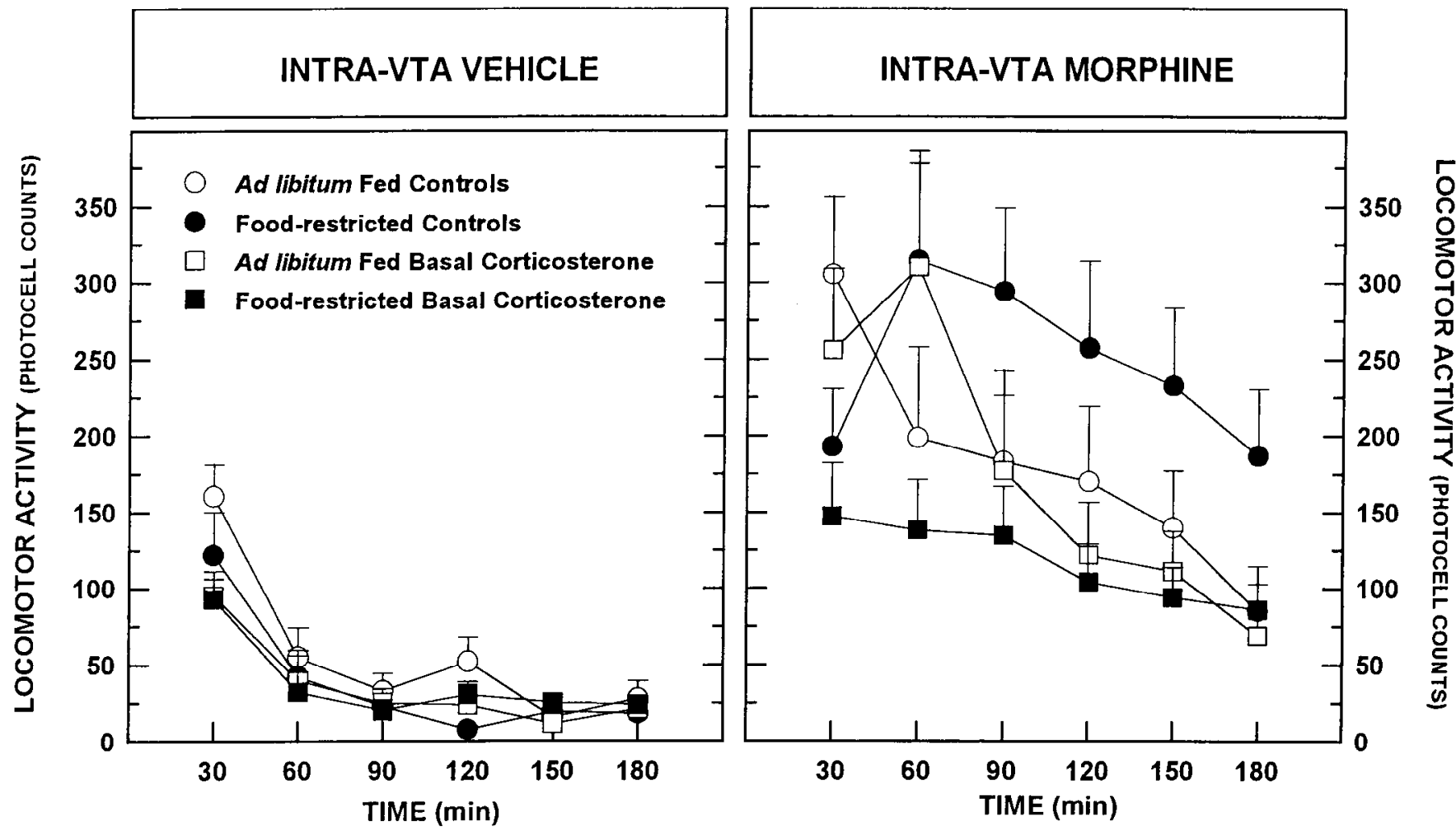

Figure 3. Effect of food restriction on the locomotor response to the intra-VTA injection of either vehicle $(1 \mu l / s i d e)$ or morphine $(1 \mu \mathrm{g} / \mathrm{side})$ in animals with an intact (Controls) or suppressed stress-induced corticosterone secretion (Basal Corticosterone). In the Basal Corticosterone groups, plasmatic levels of corticosterone were fixed in the range of basal ones by adrenalectomy and substitutive treatments. Food restriction (80\% of initial body weight) did not modify the locomotor response to vehicle in Controls and Basal Corticosterone animals. Suppression of corticosterone secretion abolished the sensitization of the locomotor response to morphine induced by food-restriction. In the Control groups, food-restricted rats had a longer locomotor response to morphine than ad libitum fed animals [Food Restriction $\times$ Time interaction, $F(5.55)=4.32, P<0.002$ ], whereas this difference disappeared in Basal Corticosterone rats. Furthermore, though ad libitum fed Basal Corticosterone and ad libitum fed Controls rats did not differ, food-restricted Basal Corticosterone animals responded significantly less to morphine than the other groups.

and behavioral indexes of central opiate transmission, as well as certain behavioral effects of morphine. Corticosterone has been found to increase the effects of enkephalin on hippocampal slices (Vidal et al., 1986), whereas adrenalectomy decreases preproenkephalin mRNA in the striatum (Chao and McEwen, 1990). In behavioral studies, it has been shown that adrenalectomy decreases the opioid form of stress- (McLeminal et al., 1982), food restriction- (Hamm et al., 1985), and brain stimulation-induced analgesia (Thorn et al., 1985), as well as morphine-induced eating (Bhakthavatsalam and Leibowitz, 1986) and locomotion (Marinelli et al., 1994).

Corticosterone may control stress-induced sensitization of dopamine-dependent effects of drugs also by acting on GABA, 5-HT, and excitatory amino acid transmission. All these neuronal systems can modulate dopamine-mediated responses to opioids and psychostimulants (Scheel-Krüger et al., 1981; Kalivas et al., 1989; Kelland et al., 1990; Pulvirenti et al., 1991) and are influenced by corticosterone. Glucocorticoids have been reported to modulate the binding capacity of 5-HT receptors (Biegon et al., 1985) and GABA receptors (Majewska et al., 1986; Majewska, 1987; Sutanto et al., 1989) and to potentiate glutamatergic transmission (Tischler et al., 1988; Sapolsky, 1990).

The multitude of possible neural substrates by which glucocorticoids can influence dopamine-dependent behaviors can explain the fact that these hormones modulate both the locomotor response to cocaine and morphine. In fact, although morphine and cocaine act through dopamine in order to increase loco- motion, their mechanism of action is very different. Cocaine is an indirect dopamine agonist that principally blocks dopamine reuptake (Reith et al., 1980; Ritz et al., 1987) and exercises its stimulant effect by acting on DA terminals, but not cell bodies. Conversely, morphine activation of DA neurons occurs in the VTA and results from the release of DA cells from an inhibitory GABA input (for review, see Kalivas and Stewart, 1991). That glucocorticoids control behavioral responses to cocaine and morphine by different mechanisms is also suggested by a recent observation. Marinelli and coworkers (1994) have shown that in adrenalectomized animals the basal, nonsensitized, locomotor response to cocaine is reinstated solely by the basal diurnal levels of corticosterone. In contrast, for morphine the reinstatement of the entire circadian secretion of the hormone is necessary.

Modulation by corticosterone of stress-induced sensitization of dopamine dependent behavioral responses to drugs extend our knowledges on the influence that these hormones exercise on vulnerability to drugs. It has been previously shown that glucocorticoids contribute to determine individual differences in the propensity to develop drug self-administration. Animals spontaneously predisposed to develop self-administration (High $\mathrm{Re}$ sponders) have a longer stress-induced secretion of corticosterone (Piazza et al., 1991b) and are more sensitive to the behavioral effects of this hormone (Piazza et al., 1993). Furthermore the administration of corticosterone to subjects that show a low predisposition to develop self-administration (Low Responders, LR) increases their propensity to self-administer amphetamine 
(Piazza et al, 1991b). The results reported here suggest that glucocorticoids play an important role not only when vulnerability is spontaneously present in certain individuals, but also when it is induced by stress. This idea is also supported by the observation that stressors that increase vulnerability to self-administer psychostimulants also prolong stress-induced corticosterone secretion (Maccari et al., 1991, 1995; Piazza et al., 1991 a,b; Deminière et al., 1992).

In conclusion, glucocorticoids may control stress-induced sensitization by modulating the sensitivity of the mesencephalic dopaminergic transmission to psychostimulants and opioids. As addictive properties of drugs seem, at least in part, mediated by their dopaminergic effects (Fibiger and Phillips, 1988; Koob and Bloom, 1988; Wise and Rompre, 1989; Le Moal and Simon, 1991; Robinson and Berridge, 1993) the present findings support the hypothesis (Piazza et al., 1991a) that glucocorticoids may increase vulnerability to drug abuse by acting on mesencephalic dopaminergic neurons.

\section{References}

Alexander BK, Coambs RB, Hadaway PF (1978) The effect of housing and gender on morphine self-administration in rats. Psychopharmacology 58:175-179.

Antelman SM, Eichler AJ, Black CA, Kocan D (1980) Interchangeability of stress and amphetamine in sensitization. Science 207:329-331.

Bhakthavatsalam P, Leibowitz SF (1986) Morphine-elicited feeding: diurnal thythm, circulating corticosterone and macronutrient selection. Pharmacol Biochem Behav 24:911-917.

Biegon A, Rainbow TC, McEwen BS (1985) Corticosterone modulation of neurotransmitter receptors in rat hippocampus: a quantitative autoradiographic study. Brain Res 33:2309-2314.

Biron D. Dauphin C. Di Paolo T (1992) Effects of adrenalectomy and glucocorticoids on rat brain dopamine receptors. Neuroendocrinology 55:468-476.

Bozarth MA, Murray A, Wise RA (1989) Influence of housing conditions on intravenous heroin and cocaine self-administration in rats. Pharmacol Biochem Behav 33:903-907.

Broocks A, Schweiger U, Pirkc KM (1990) Hypcractivity aggravates semistarvation-induced changes in corticosterone and triiodothyronine concentrations in plasma but not luteinizing hormone and testosterone levels. Physiol Behav 48:567-569.

Campbell BA, Fibiger HC (1971) Potentiation of amphetamine-induced arousal by starvation. Nature 233:424-425.

Carroll ME (1982) Rapid acquisition of oral phencyclidine self-administration in food-deprived and food-satiated rhesus monkeys: concurrent phencyclidine and water choice. Pharmacol Biochem Behav 17: 341-346.

Carroll ME, Meisch RA (1981) Determinants of increased drug selfadministration due to food deprivation. Psychopharmacology 74:197200

Carroll ME, France CP and Meisch RA (1979) Food deprivation increases oral and intravenous drug intake in rats. Science 205:319-321.

Chao HM, McEwen BS (1990) Glucocorticoid regulation of preproenkephalin messenger ribonucleic acid in the rat striatum. Endocrinology 126:3124-3130.

Delfs JM, Schreiber L, Kelley AE (1990) Microinjection of cocaine into the nucleus accumbens elicits locomotor activation in the rat. $\mathrm{J}$ Neurosci 10:303-310.

Deminière JM, Piazza PV, Guegan G, Abrous N, Maccari S, Le Moal M. Simon H (1992) Increased locomotor response to novelty and propensity to intravenous self-administration in adult offspring of stressed mothers. Brain Res 586:135-139.

Deroche V, Piazza PV, Casolini P, Maccari S, Le Moal M, Simon H (1992a) Stress-induced sensitization to amphetamine and morphine psychomotor effects depend on stress-induced corticosterone secretion. Brain Res 598:343-348.

Deroche V, Piazza PV, Maccari S, Le Moal M, Simon H (1992b) Repeated corticosterone administration sensitizes the locomotor response to amphetamine. Brain Res 584:309-313.

Deroche V, Piazza PV, Casolini P, Le Moal M, Simon H (1993a) Sensitization to the psychomotor effects of amphetamine and morphine induced by food restriction depends on corticosterone secretion. Brain Res 611:352-356.

Deroche V, Piazza PV, Le Moal M, Simon H (1993b) Individual differences in the psychomotor effects of morphine are predicted by reactivity to novelty and influenced by corticosterone secretion. Brain Res 623:341-344.

Deroche V, Piazza PV, Le Moal M, Simon H (1994) Social isolationinduced enhancement of the psychomotor effects of morphine depends on corticosterone secretion. Brain Res 640:136-139.

De Vry J, Donselaar I, Van Ree JM (1989) Food deprivation and acquisition of intravenous cocaine self-administration in rats: effects of naltrexone and haloperidol. J Pharmacol Exp Ther 251:735-740.

Faunt JE, Crocker AD (1988) Adrenocortical hormone status affects responses to dopamine receptor agonists. Eur J Pharmacol 152:255-261.

Faunt JE, Crocker AD (1989) Effects of adrenalectomy on responses mediated by dopamine D- 1 and D-2 receptors. Eur J Pharmacol 162: 237-244.

Fibiger HC, Phillips AG (1988) Mesocorticolimbic dopamine systems and reward. Ann NY Acad Sci 537:206-215.

Gilad GM, Rabey JM, Gilad VI (1987) Presynaptic effects of glucocorticoids on dopaminergic and cholinergic synaptosomes. Implications for rapid endocrine-neural interactions in stress. Life Sci 40: $2401-2408$

Goeders NE, Guerin GF (1994) Non-contingent electric footshock facilitates the acquisition of intravenous cocaine self-administration in rats. Psychopharmacology 114:63-70.

Hadaway PF, Alexander BK, Coambs RB, Beyerstein B (1979) The effect of housing and gender on preference for morphine-sucrose solutions in rats. Psychopharmacology 66:87-91.

Hamm RJ, Knisely JS, Watson A, Lyeth BG, Bossut DFB (1985) Hormonal mediation of the analgesia produced by food deprivation. Physiol Behav 35:879-882.

Haarfstrand A, Fuxe K, Cintra A, Agnati AF, Zini I, Wilkström AC, Okret S, Yu ZY, Goldstein M, Steinbuch H, Verhöfstad A, Gustafsson JA (1986) Glucocorticoid receptor immunoreactivity in monoaminergic neurons of rat brain. Proc Natl Acad Sci USA 83:9779-9783.

Hooks MS, Jones GH, Neill DB, Justice JB Jr (1991a) Individual differences in amphetamine sensitization: dose dependent effects. Pharmacol Biochem Behav 41:203-210.

Hooks MS, Jones GH, Smith AD, Neill DB, Justice JB Jr (199lb) Response to novelty predicts the locomotor and nucleus accumbens dopannine response to cocaine. Synapse 9:121-128.

Ho-Van-Hap A, Babineau LM, Berlinguet L (1967) Hormonal action on monoamine oxidase activity in rats. Can J Biochem 45:355.

Imperato A, Puglisi-Allegra S, Casolini P, Zocchi A, Angelucci L (1989) Stress-induced enhancement of dopamine and acetylcholine release in limbic structure role of corticosterone. Eur J Pharmacol 165:337-339.

Joyce EM, Iversen SD (1979) The effect of morphine applied locally to mesencephalic dopamine cell bodies on spontaneous motor activity in the rat. Neurosci Lett 14:207-212.

Kalivas PW (1985) Sensitization to repeated enkephalin administration into the ventral tegmental area of the rat. II. Involvement of the mesolimbic dopamine system. J Pharmacol Exp Ther 225:544-550.

Kalivas PW, Stewart J (1991) Dopamine transmission in the initiation and expression of drug- and stress-induced sensitization of motor activity. Brain Res Rev 16:223-244.

Kalivas PW, Widerlöv E, Stanley D, Breese G. Prange AJ Jr (1983) Enkephalin action on the mesolimbic system: a dopamine-dependent and dopamine-independent increase in locomotor activity. J Pharmacol Exp Ther 227:229 237.

Kalivas PW, Duffy P, Barrow J (1989) Regulation of the mesocorticolimbic dopamine system by glutamic acid receptor subtypes. J Pharmacol Exp Ther 251:378-387.

Kelland MD, Freeman AS, Chiodo LA (1990) Serotoninergic afferent regulation of the basic physiology and pharmacological responsiveness of nigrostriatal dopamine neurons. J Pharmacol Exp Ther 253: 803-811.

Kelly PH, Iversen SD (1976) Selective 6-OHDA-induced destruction of mesolimbic dopamine neurons: abolition of psychostimulant-induced locomotor activity in rats. Eur J Pharmacol 40:45-56.

Knuth UA, Friesen IIG (1983) Changes of beta-endorphin and somatostatin concentrations in different hypothalamic areas of female rats after chronic starvation. Life Sci 33:827-833. 
Koob GF, Bloum FE (1988) Cellular and molecular mechanisms of drug dependence. Science 242:715-723.

Le Moal M, Simon H (1991) Mesocorticolimbic dopamine network: functional and regulatory roles. Physiol Rev 71:155-234.

Maccari S, Piazza PV, Deminière JM, Lemaire V, Mormède P, Simon H, Angelucci L, Le Moal M (1991) Life events-induced decrease of type I corticosteroid receptors is associated with a decrease of corticosterone feedback and an increase of the vulnerability to amphetamine self-administration. Brain Res 547:7-12.

Maccari S, Piazza PV, Kabbaj M, Barbazange A, Simon H, Le Moal M (1995) Adoption reverses the long-term impairment in glucocorticoid feedback induced by prenatal stress. J Neurosci 15:110-116.

Majewska MD (1987) Antagonist-type interaction of glucocorticoids with the GABA receptor-coupled chloride channel. Brain Res 418: 377-382.

Majewska MD, Harrison NL, Schwartz RD, Barker JL, Paul SM (1986) Steroid hormone metabolites are barbiturate-like modulators of the GABA receptors. Science 232:1004-1007.

Marinelli M, Piazza PV, Deroche V, Maccari S, Le Moal M, Simon H (1994) Corticosterone circadian secretion differentially facilitates dopamine-mediated psychomotor effect of cocaine and morphine. J Neurosci 14:2724-2731.

McLennan AJ, Drugan RC, Hyson RL, Maier SF, Madden JD and Barchas JD (1982) Corticosterone: a critical factor in an opioid form of stress-induced analgesia. Science 215:1530-1532.

Meyer JS, Micco DJ, Stephenson BS, Krey LC, McEwen BS (1979) Subcutaneous implantation method for chronic glucocorticoid replacement therapy. Physiol Behav 22:867-870.

Mittleman GM, Blaha CD, Phillips AG (1992) Pituitary-adrenal and dopaminergic modulation of schedule-induced polydipsia: behavioral and neurochemical evidence. Behav Neurosci 106:402-408.

Papasava M, Singer G (1985) Self-administration of low-dose cocaine by rats at reduced and recovered body weight. Psychopharmacology $85: 419-425$

Pellegrino LJ, Pellegrino AS, Cushman AJ (1979) A stereotaxic atlas of the brain. New York: Plenum.

Piaz7a PV, Deminière IM, Le Moal M, Simon H (1989) Factors that predict individual vulnerability to amphetamine self-administration. Science 245:1511-1513

Piazza PV, Deminière JM, Le Moal M, Simon H (1990) Stress- and pharmacologically-induced behavioral sensitization increases vulnerability to acquisition of amphetamine self-administration. Brain Res 514:22-26.

Piazza PV, Deminière JM, Maccari S, Le Moal M, Mormède P, Simon H (1991a) Individual vulnerability to drugs self-administration: action of corticosterone on dopaminergic systems as a possible pathophysiological mechanism. In: The mesolimbic dopamine system: from motivation to action (Wilner P, Scheel-Krüger J, eds), pp 473495. Chichester: Wiley.

Piazza PV, Maccari S, Deminiere JM, Le Moal M, Mormede P, Simon H (1991b) Corticosterone levels determine individual vulnerability to amphetamine self-administration. Proc Natl Acad Sci USA 88: 2088-2092.

Piazza PV, Deroche V, Deminiere JM, Maccari S, Le Moal M, Simon $\mathrm{H}$ (1993) Reinforcing properties of corticosterone demonstrated by intravenous self-administration. Possible biological basis of sensation-seeking. Proc Natl Acad Sci USA 90:11738-11742.

Post RM, Weiss SRB, Pert A (1988) Cocaine-induced behavioral sensitization and kindling: implications for the emergence of psychopathology and seizure. In: The mesocorticolimbic dopaminergic system (Kalivas PW, Nemeroff CB, eds), pp 292-308. New York: New York Academy of Sciences.

Pulvirenti L, Swerdlow NR, Hubner CB, Koob GF (1991) The role of limbic-accumbens-pallidal circuitry in the activating and reinforcing properties of psychostimulant drugs. In: The mesolimbic dopamine system: from motivation to action (Wilner P, Scheel-Krüger J, eds), pp 131-139. Chichester: Wiley.

Reith MEA, Shersen H, Lajtha A (1980) Saturable [ $\left.{ }^{3} \mathrm{H}\right]$-cocaine binding in central nervous system of mouse. Life Sci 27:1055-1062.
Ritz MC, Lamb RJ, Goldberg SR, Kuhar MJ (1987) Cocaine receptors on dopamine transporters are related to self-administration of cocaine. Science 237:1219-1223.

Robinson TE, Becker JB (1986) Enduring changes in brain and behavior produced by chronic amphetamine administration: a review and evaluation of animal models of amphetamine psychosis. Brain Res Rev 11:157-198.

Robinson TE, Berridge KC (1993) The neural basis of drug craving: an incentive sensitization theory of addiction. Brain Res Rev 18:247-291.

Rothschild AJ, Langlais PJ, Schatzberg AF, Miller MM, Saloman MS, Lerbinger JE, Cole JO, Bird E (1985) The effect of a single acute dose of dexamethasone on monoamine and metabolite levels in the rat brain. Life Sci 36:2491-2505.

Sapolsky RM (1990) Glucocorticoids, hippocampal damage and the glutamatergic synapse. Prog Brain Res 86:12-23.

Scheel-Kraager J, Magelund G, Olianas MC (1981) Role of GABA in the striatal output system: globus pallidus, nucleus endopeduncolaris, substantia nigra and nucleus subthalamicus. In: GABA and the basal ganglia (Di Chiara G, Gessa GL, eds), pp 165-186. New York: Raven.

Schenk S, Lacelle G, Gorman K, Amit Z (1987) Cocaine self-administration in rats influenced by environmental conditions: implications for the etiology of drug abuse. Neurosci Lett 81:227-231.

Shaham Y, Stewart J (1994) Exposure to mild stress enhances the reinforcing efficacy of intravenous heroine self-administration in rats. Psychopharmacology 523-527.

Shaham Y, Alvarez K, Nespor SM, Grundberg NE (1992) Effect of stress on oral morphine and fentanyl self-administration in rats. Pharmacol Biochem Behav 41:615-619.

Sorg BA, Kalivas PW (1991) Behavioral and neurochemical crosssensitization between footshock stress and cocaine. Brain Res 559: 29-36.

Stewart J, Badiani A (1993) Tolerance and sensitization to the behavioral effects of drugs. Behav Pharmacol 4:289-3/2.

Stewart J, Vezina P (1989) Microinjections of SCH-23390 into the ventral tegmental area and substantia nigra pars reticulata atenuate the development of sensitization to the locomotor activating effects of systemic amphetamine. Brain Res 495:401-406.

Sutanto W, Handelmann G, De Bree F, De Kloet ER (1989) Multifaceted interaction of corticosteroids with the intracellular receptors and with membrane GABA-A recptor complex in the rat brain. J Neuroendocrinol 1:243-247.

Thorn BE, Bailey RL, Butler RW (1985) Adrenalectomy attenuates stimulation-produced analgesia. Neuropharmacology 24:655-657.

Tischler ME, Henriksen EJ, Cook PH (1988) Role of glucocorticoids in increased muscle glutamine production instarvation. Muscle Nerve 11:752-756

Tsujii S, Nakai Y, Fukata J, Koh T, Takahashi H, Usui T, Imura H (1986a) Effects of food deprivation and high fat diet on opioid receptor binding in rat brain. Neurosci Lett 72:169-173.

Tsujii S, Nakai Y, Koh T, Takahashi H, Usui T, Ikeda H, Matsuo T, Imura $H$ (1986b) Effect of food deprivation on opioid receptor binding in the brain of lean and fatty Zucker rats. Brain Res 399:200-203.

Vaswani KK, Tejwani GA (1986) Food deprivation-induced changes in the level of opioid peptides in the pituitary and brain of rat. Life Sci 38:197-201.

Versteeg DHG, Van Zoest I, De Kloet ER (1983) Acute changes in dopamine metabolism in the medial basal hypothalamus following adrenalectomy. Experentia 40:112-114.

Vezina P, Stewart J (1984) Conditioning and place-specific sensitization of increases in activity induced by morphine in the VTA. Pharmacol Biochem Behav 20:925-934.

Vezina P, Stewart J (1989) The effect of dopamine receptor blockade on the development of sensitization to the locomotor activating effects of amphetamine and morphine. Brain Res 499:108-120.

Vidal C, Jordan W, Ziegelgänsberger W (1986) Corticosterone reduces the excitability of hippocampal pyramidal cells in vitro. Brain Res 383:54-59.

Wise RA, Rompre PP (1989) Brain dopamine and reward. Annu Rev Psychol 40:191-225. 